\title{
Spontaneous Renal Artery Pseudoaneurysm Treated By Arterial Embolization
}

Mohammed Habib ${ }^{1^{*}}$, Majdy Ayyad ${ }^{1}$, Mohammed Balosha ${ }^{2}$

${ }^{1}$ Cardiology Department- Alshifa Hospital- Gaza- Palestine, Israel

${ }^{2}$ Radiology Department- Alshifa Hospital- Gaza- Palsetine, Israel

*Corresponding Author: Mohammed Habib, Cardiology Department-Alshifa Hospital- Gaza- Palestine, Israel

Received date: November 08, 2019; Accepted date: December 28, 2019; Published date: January 05, 2020.

Citation: Mohammed H, Majdy A, Mohammed B. (2020) Spontaneous Renal Artery Pseudoaneurysm Treated by Arterial Embolization.J Clin Imag. Interven Radiology, 2(1); Doi:10.31579/2642-1674/009

Copyright: (2020 Mohammed $\mathrm{H}$. This is an open-access article distributed under the terms of The Creative Commons Attribution License, which permits unrestricted use, distribution, and reproduction in any medium, provided the original author and source are credited.

\begin{abstract}
Renal artery pseudoaneurysm is a rare vascular lesion. It is found with increasing frequency as a result of unrelated abdominal imaging or on work-up for hypertension. The pseudoaneurysm can be defined as a pulsatile hematoma that communicates with the artery through a small hole in the arterial wall. However, the rupture of pseudoaneurysmis the most dreaded complication because it causes death. There are many causes of renal artery pseudoaneurysm and are generally related to renal biopsy, nephrectomy or percutaneous procedures. In addition, there is a relationship with penetrating traumas and, more rarely, with blunt traumas. We report a case of renal artery pseudoaneurysm treated successfully with vascular plug embolization. A 22-year-old woman with hypertension presented with an incidental left renal artery pseudoaneurysm measuring $35 \times 23 \mathrm{~mm}$. We successfully performed endovascular treatment with vascular plug embolization without any complications.
\end{abstract}

Keywords: renal artery pseudoaneurysms; vascular plug embolization

\section{Introduction}

Renal arterial pseudoaneurysm is a haematoma contained by the surrounding structures outside the vessel wall. (1) The incidence is low, the overall incidence ranges between $0.01 \%$ and $1 \%$ (2). This increases to $2.5 \%$ when only patients with systemic hypertension are considered (3).

The renal artery pseudoaneurysm etiologically are associated with intervention procedures such as partial nephrectomy, percutaneous procedures, renal biopsy. But can be related to penetrating trauma and more rarely blunt trauma. (4-5). Although it may be spontaneous as described in this case without history of trauma, renal surgery, percutaneous procedures, as well as inflammatory and neoplastic processes within the kidney.

\section{Case report}

A 22-year-old woman visited the cardiology department with headache and systemic hypertension abdominal pain and bloody stool. She had been taking antihypertensive medicine for 2 years, and her blood pressure was well uncontrolled. On admission, her vital signs were as follows: blood pressure, 178/110 $\mathrm{mmHg}$; heart rate $78 \mathrm{bpm}$; respiratory rate, $20 \mathrm{bpm}$; and body temperature, 37.5 and physical examination did not reveal any abnormalities. Her complete blood count revealed the following: hemoglobin level, 11.9 $\mathrm{g} / \mathrm{dL}$; white blood cell count, 6,580/mm3; and platelet count, 218,000/mm3. A basic metabolic panel revealed no abnormalities; her creatinine level was 0.97 $\mathrm{mg} / \mathrm{dL}$. She take valsartan/hydrochlorothiazide $(160 / 25) \mathrm{mg}$ tablet and $5 \mathrm{mg}$ bisoprolol medication to control high blood pressure She was not any past medical histories including trauma, renal surgery, percutaneous procedures, as well as inflammatory and neoplastic processes within the kidney.

Her abdominal CT angiography revealed a $2.3 \times 3.5 \mathrm{~cm}$ sized left renal artery saccular pseudoaneurysm. A left renal artery pseudoaneurysm was observed near the proximal part of the inferior branch on the angiogram.

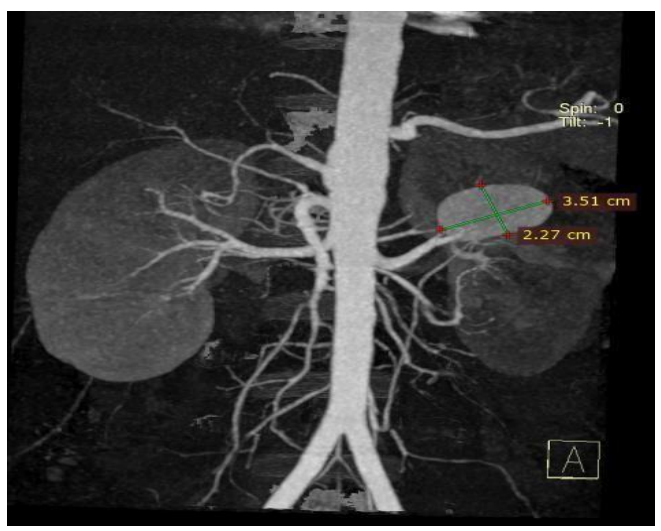

Figure 1: CT angiography revealed an $2.3 \times 3.5 \mathrm{~cm}$ sized left renal artery saccular pseudoaneurysm. 
Selective left renal angiography was done and suggested pseudoaneurysm at the proximal inferior branch of the left renal artery. We inserted a vascular plug $6 \times 7 \mathrm{~mm}$ and deployed at the proximal inferior branch of the left renal artery (Figure. 2,3). There were no complications of endovascular treatment.

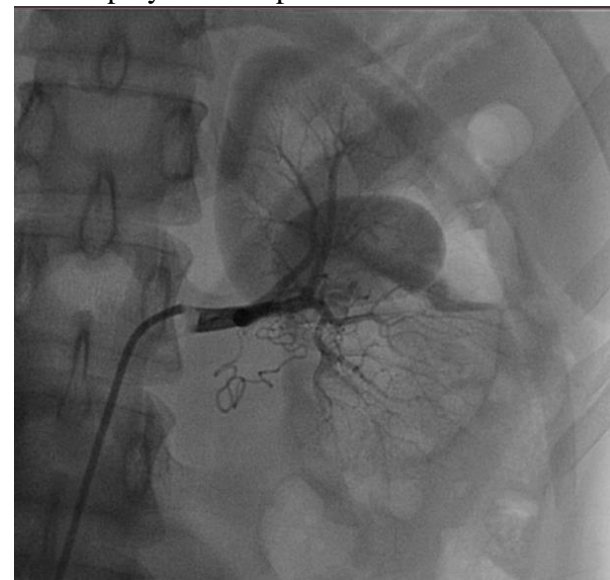

Figure 2: Selective left renal angiography was done and suggested pseudoaneurysm at the proximal inferior branch of the Left renal artery

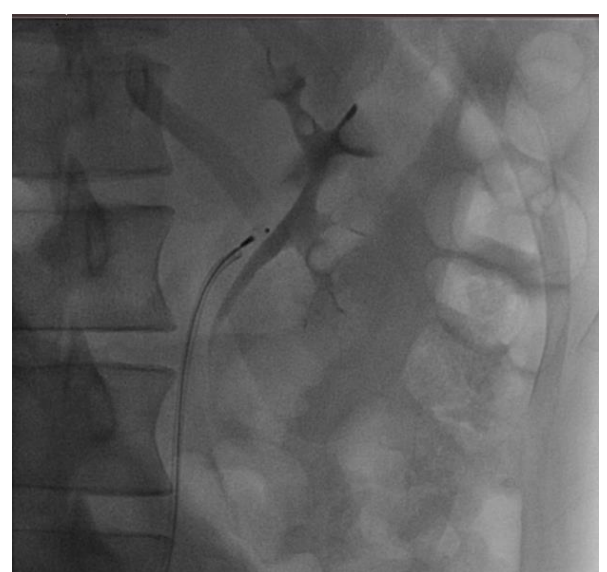

Figure 3: vascular plug deployment at the neck of pseudoaneurysm

\section{Discussion}

The incidence of renal artery pseudoaneurysm in patient with hypertension unresponsive to medical therapy can be as high as 39\% (6) the etiologies of pseudoaneurysm are long standing untreated hypertension, surgical manipulation (open, laparoscopic, and/or endovascular) blunt and penetrating trauma, infectious angiomyolipomas (i.e., mycotic), polyarteritis nodosa , malignancy, radiation, and/or cyclophosphamide use $(7,8)$. The risk of rupture is thought to vary inversely with size, and most investigators agree that an aneurysm exceeding $2 \mathrm{~cm}$ is more likely to undergo rupture and interventions are indicated in pseudoaneurysms greater than $2 \mathrm{~cm}$, or when associated with complications such as severe hemorrhage and renovascular hypertension. (9)

Indications for treatment include uncontrolled hypertension, progressive enlargement, with size $>2$ to $2.5 \mathrm{~cm}$ or size $>1 \mathrm{~cm}$ in a female of childbearing age (10). Currently, endovascular $r$ treatments include embolization (coils, gelfom or alcohol) or stenting across the aneurysm is the intervention of choice in elective circumstances (11).

\section{Conclusion}

We report a case of left renal artery pseudoaneurysm with severe uncontrolled systemic hypertension in a young female who did not control high blood pressure for a 2 years was treated successfully of vascular plug system. To the best of our knowledge this is the first report of a spontaneous renal artery pseudoaneurysm with no predisposing factors and was managed by selective arteriography and embolisation using vascular plug.

clinicallymimicking renal colic: diagnosis with multidetector CT. Br J Radiol.;80:e262-264

7. Myung-Sung Kim, Young-Bae Lee, Jae-Hyuk Lee, JaeHyuk Lee,Chae-Wan Lim (2015). Spontaneous rupture of a renal artery pseudoaneurysm in a previously hypertensive patient. Clinical Hypertension. 21:4

8. Mohammed Habib, Mohammed Hillis, Majed Shunnat.(2019) Transarterial Embolization for Renal Hemorrhage after Percutaneous Nephrolithotomy. Journal of Advances in Medicine and Medical Research. 29(5): 14.

9. Galego SJ, Barbato H, Corrêa JA, Kafejian O, Polimanti AC, et al.(2004). Pseudoaneurisma de artéria renal pósendop-ielotomia retrógrada: relato de caso e revisão de literatura. J Vasc Br; 3:285- 287.

10. Hughes JH, Stanisic TH, Buster D, Nagle RB.(1980). Massive nontraumatichematuria: a challenge demanding immediate action. Postgrad Med.; 67:97-106.

11. Ishizuka O, Takayama F, Sone S. (2006) Large renal aneurysm successfully treatedby percutaneous embolization using detachable steel coils. Int J Urol.; 13:993-994. 
Ready to submit your research? Choose Auctores and benefit from:

* fast, convenient online submission

* rigorous peer review by experienced research in your field

* rapid publication on acceptance

* authors retain copyrights

* unique DOI for all articles

* immediate, unrestricted online access

To Submit Your Article Click Here: Submit Article

At Auctores, research is always in progress.

DOI: $10.31579 / 2642-1674 / 009$

Learn more https://www.auctoresonline.org/journals/clinical-imagingand-interventional-radiology 